\title{
Response Path Adapted to the Unbalanced Shrinkage of Small Towns in Metropolitan Areas
}

\author{
A case study of Wuhan in China \\ Yanqun LI, Huazhong University of Science and Technology; China \\ Hong GENG, Huazhong University of Science and Technology; China (Corresponding author) \\ Erpeng SHI, Huazhong University of Science and Technology;
}

\begin{abstract}
Along with the global wave of urbanization, urban agglomerations with megacities as the core have become the main form of urbanization in various countries. The polarization effect around the metropolis leads to the centripetal flow of capital, labour, land and other resource elements in the surrounding small towns, which causes the shrinkage of small towns in the metropolis, such as population reduction, economic recession, idle housing and dilapidated space. The shrinkage of small towns in the metropolis has become a global issue. However, as an important spatial unit in the spectrum of urbanization that serves, connects and couples urban and rural areas, the shrinking phenomenon faced by small towns has an important influence on the healthy development of urbanization. Exploring the development path of adaptive shrinkage for small towns has become an important part of the healthy urbanization of metropolises.

Based on the public data of population, land and economy in Wuhan, China from 2004 to 2014, this paper uses GIS and other spatial analysis technologies to comprehensively measure the relevant characteristics of the shrinkage of small towns. The results showed that the small towns in Wuhan are in the form of "unbalanced shrinkage" under a local growth. And the towns present a spatial pattern of "circle increasing shrinkage" around the boundary of main downtown. With a further exploration of the formation mechanism of "unbalanced shrinkage", it is found that this shrinkage pattern is caused by a combination function of various factors, such as downtown deprivation in the policies supply, centripetal delivery of social capital and reconstruction of regional division of labour network. Based on this, this paper tries to propose some response paths for small towns in metropolitan areas to adapt to the "unbalanced shrinkage". First of all, the small towns should integrate into the regional differential development pattern and strive for the institutional dividend. Secondly, the small towns should promote an industrial transformation, and then attract the market release of social capital. Thirdly, the small towns should improve the living environment and promote intensive use of land. Through these paths, we can stabilize the three-level structure system of "urban-township-village", and ensure the healthy urbanization of metropolitan areas.
\end{abstract}




\section{Keywords}

Small towns, Unbalanced shrinkage, Circle increasing pattern, Formation mechanism, Wuhan

\section{Introduction}

Along with the global wave of urbanization, urban agglomerations with megacities as the core have become the main form of urbanization in various countries. More than 55 percent of the world's population live in the urban agglomerations. The polarization effect around the metropolis leads to the centripetal flow of capital, labour, land and other resource elements in the surrounding small towns, which causes the shrinkage of small towns in the metropolis, such as population reduction, economic recession, idle housing and dilapidated space. Countries such as the United States, Germany, France, Japan and the Netherlands are generally facing the shrinking plight of the development momentum of small towns (Oswalt 2006, Johnson 2006, Glock 2004, Ortiz-Moya 2015 \& Bontje 2012). The shrinkage of small towns in the metropolis has become a global issue. A comprehensive comparison of the development characteristics shows that there are significant differences in the types, characteristics and mechanisms of the shrinkage of small towns in different countries. For example, the shrinking small towns in both the United States and Japan are located in suburban, but the United States shows the phenomenon of poverty agglomeration and middle class outflow, while Japan shows the phenomenon of functional decline (Downs 1997 \& Saori and Polivka 2008). The shrinking small towns in Germany are mainly concentrated in East Germany, showing the phenomenon of continuous decrease in population and employment rate, and spreading to West Germany (CHEN, et al. 2018).

In the context of China's localized development, it is found that the general growth and local shrinkage in China's rapid urbanization process have become the normal, with the economy entering the new normal (DU and LI 2018). For small towns in metropolitan areas, it shows local shrinkage under the overall urban growth. Specifically, Chinese metropolises are still showing a strong growth trend, and small towns still have a strong development potential on the whole. However, on the one hand, the outflow of labour force, the hollowing out of families and the aging of population have reduced the population vitality of small towns, while the convenient urban transportation network has provided the opportunity for township residents to go to the city for over-consumption, which has compressed the local consumption market and business service level of small towns. On the other hand, the government finance and social capital traditionally invested in small towns turn to the central supply driven by the value-added in the central city, leading to the market risk of small town businesses facing the transfer, withdrawal and withdrawal of business entities (GAO, et al 2019). Under the combined action of internal and external forces, some small towns in China's metropolitan areas show multi-dimensional shrinkage of population, space, economy and ecology, including the outflow and aging of labour force in the population dimension, hollowness and index deprivation in the spatial dimension, imperfect industrial development in the economic dimension, systematic low-level consumption in the ecological dimension and other external manifestations (DU and LI 2017, LIU and YANG 2017, LI and GENG 2018). Public and micro survey data show that more than $45 \%$ of the small towns in China's metropolitan areas have a new spatial pattern of "growth and shrinkage" co-existing 
in a certain degree (LI, et al 2019). However, as an important spatial unit in the spectrum of urbanization that serves, connects and couples urban and rural areas, the shrinking phenomenon faced by small towns has an important influence on the healthy development of urbanization. Exploring the development path of adaptive shrinkage for small towns has become an important part of the healthy urbanization of metropolises.

Located in central China, Wuhan is the central city of Wuhan city circle, with a population of more than 12 million and a total area of $8,848 \mathrm{~km}^{2}$. Over the past 20 years, Wuhan has become a typical metropolitan area in China, relying on its strong absorption capacity of population and economic resources. However, during the development, the small towns in Wuhan metropolitan area is faced with the simultaneous competition of Yangtze River Delta Urban Agglomeration and Pearl River Delta, and also faced with the challenge of resource backflow under the strategy of rural vitalization. It leads to irregular flow of urban and rural resources such as population and capital. As a typical area that has experienced the "collapse of the central region" and "rise of the central region", and also experienced frequent population migration, the small towns in Wuhan metropolitan area show remarkable logic of growth and shrinkage.

Based on the above, by taking small towns in Wuhan metropolitan area as the research object, this research uses the government open statistical data, supplemented by some micro survey data, to identify the growth and shrinkage pattern of small towns in Wuhan metropolitan area. Then the research analyses the phenomenon and formation mechanism of the growth and shrinkage of small towns in Wuhan metropolitan area, and puts forward the adaptive planning response path to promote the healthy development of small towns in metropolitan area.

\section{Methodology}

\subsection{Analytical Framework}

Population change is widely used internationally as the main criterion to measure whether the towns shrink or not (Oswalt, et al. 2006). The Shrinking City International Research Network (SCIRN) defines shrinking towns as "areas with a population of at least 10,000 , most of which should experience population decline for more than two years, accompanied by structural economic transformation and crisis" (Wiechmann 2008; Hollander, et al. 2009). However, as a complex system with overlapping factors of population, land and economy, it is limited to evaluate the shrinkage of small towns simply by population index. If the development of small towns is regarded as the flow and agglomeration of capital, labour and other production factors in the built space (Bertinelli et al. 2004), then the shrinkage of small towns should be understood as the spatial decay caused by the outflow and relocation of capital, labour and other mobile production factors ( $\mathrm{Du}$, et al. 2017). It is proposed in relevant studies that town's shrinkage has economic, population and spatial dimensions, which can be used to emphasize multidimensional processes and effects (Martez-fernandez et al. 2012). Based on the above, population, economy and land are selected as the index dimensions to evaluate the shrinkage of small towns in this study, with a view to systematically explain the phenomenon of shrinkage of small towns. 


\subsection{Research Method}

Based on the above, a three-dimensional comprehensive index system of population, economy and land was firstly established. The comprehensive index system includes eight indexes, which are: total population, urbanization rate, regional GDP, total fixed asset investments, local fiscal revenue, built-up area, population density, and area of public green space. Then, all the indexes are standardized, and the weight of indexes is determined by means of "Standard Deviation Decision" (Wang 1999), so as to avoid the influence of each index dimension and subjective assignment (formula (1)). And then, the comprehensive development index of small towns is calculated according to the formula (2), and the shrinkage degree of small towns is characterized according to the change of the comprehensive development index of small towns in different years, seen in formula (3).

$$
\begin{aligned}
& W_{j}=\sigma\left(\text { Index }_{j}\right) / \sum_{j=1}^{m} \sigma\left(\text { Index }_{j}\right) \\
& \text { Index }_{i}=\sum_{j=1}^{m} X_{i j} W_{j} \\
& \text { Shrinkage }=\Delta_{\text {Index }}^{j=1}=\text { Index } x_{i t 1}-\text { Index } i \text { it2 }
\end{aligned}
$$

\subsection{Data Source}

This research takes all the small towns in the six remote districts of Wuhan except the Chengguan Towns as the research objects, with a total of 58. The six districts are as Huangpi district (located in the north of Wuhan, contains 16 towns), Xinzhou district (located in the northeast of Wuhan, contains 13 towns), Jiangxia district (located in the south of Wuhan, contains 10 towns), Dongxihu district (located in the west of Wuhan, contains 6 towns), Caidian district (located in the west of Wuhan, contains 10 towns), and Hannan district (located in the southwest of Wuhan, contains 3 towns). With a comprehensive consideration of the urbanization process and characteristics of both China and Wuhan, this research selects the year of 2004, 2009 and 2014 as the time points of indicator measurement. The demographic and economic data of research evaluation indexes are all directly or indirectly derived from the statistical yearbook of Wuhan and six districts, supplemented by relevant data obtained from field observation and questionnaire survey. The land data are derived from the built-up area patches downloaded from the Google map.

\section{Result}

\subsection{Comprehensive Development Index of Small Towns}

Through the use of population, economy, land and other relevant data of the year 2004, 2009 and 2014, the comprehensive development index of small towns in Wuhan was measured, and the spatial distribution map of the comprehensive development index of small towns in corresponding years was drawn (Fig.1). The results show that the overall difference of the comprehensive development index of small towns in Wuhan in 2004 is small, with a spatial pattern of "high in the north and low in the south". The small towns with high comprehensive development index are mainly concentrated in the north of Wuhan, including Yangluo and Xinchong in Xinzhou district, and Shekou, Tianhe, Hengdian in Huangpi district. In 2009, the north-south difference in the comprehensive development index of small towns in Wuhan gradually weakened. Small towns with high comprehensive development index are concentrated in the north of Wuhan. Especially Yangluo and Shekou have become the significant growth poles. However, the comprehensive development index of small towns far 
away from the main downtown have showed a decreasing trend, such as Mulan, Xiaosi, Sandian, Jiujie and so on. By 2014, the comprehensive development index of small towns in wuhan has formed a spatial structure of "decline of circle layer" which rings the main downtown, that is, the closer to the main downtown, the higher the comprehensive development index is; the farther away you are from the main downtown, the lower the composite development index. The first circle layer consists small towns surrounding the main downtown, including Yangluo, Wuhu, Shekou, Tianhe, Jinghe, Zoumaling, Zhashan, Zhengdian, etc. The second circle layer refers to the small towns located in the middle of six districts, including small towns such as Shuangliu, Wangji, Cangbu, Liuzhi, Qijiawan, Yuxian, Jinkou, Dazhi and so on. The third circle layer is located at the edge of Wuhan. And the small towns present continuous spatial pattern with small comprehensive development index, mainly concentrated in the north of Huangpi district, the north of Xinzhou district, the south of Jiangxia district and the west of Caidian district.

At the district level, the differences in the comprehensive development index of small towns in six districts of Wuhan were relatively small in the early days. However, by 2009, the comprehensive development index of small towns in various districts showed a polarization trend and the differences were significantly enlarged. Till 2014, the differences in the comprehensive development index of small towns among different districts gradually narrowed. But there were significant polarizations in the small towns within the six districts, which was manifested as the spatial pattern of the declining circle layer of the comprehensive development index of small towns from the main downtown to the outside.

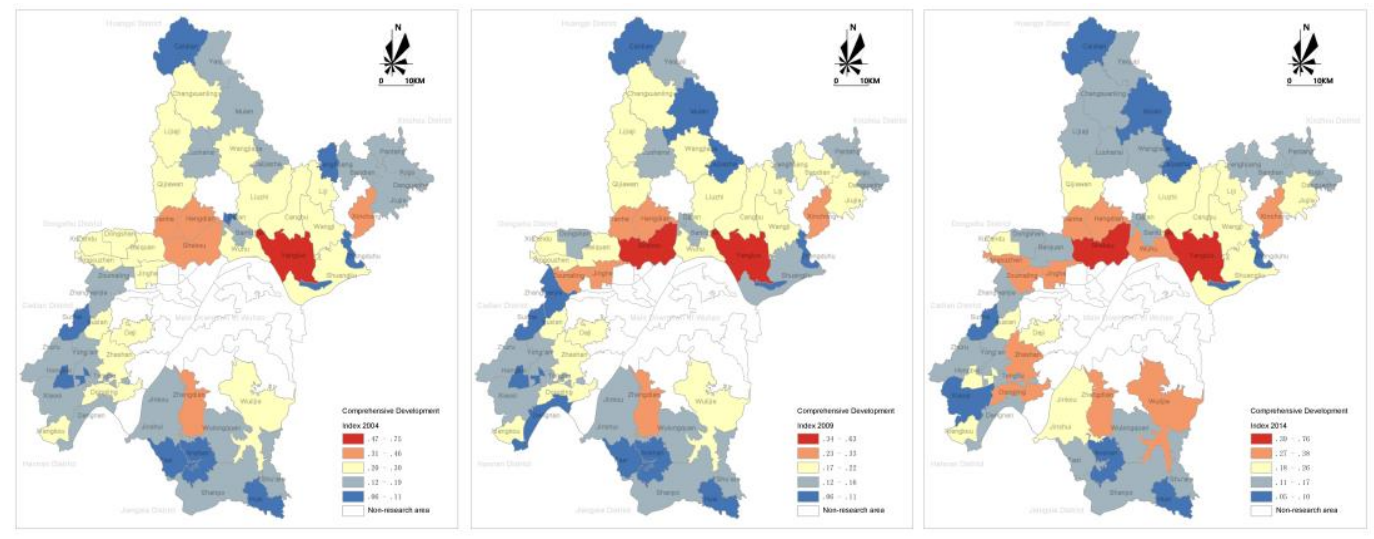

Figure 1 Spatial difference of comprehensive development index of small towns in Wuhan

By comparing the calculated results of the comprehensive development index of small towns with the spatial distribution characteristics of retail business in Wuhan (FIG.2), it is found that the calculated results of the comprehensive development index of small towns are highly consistent with the spatial distribution characteristics of economic industry, so as to further verify the authenticity of the comprehensive development index

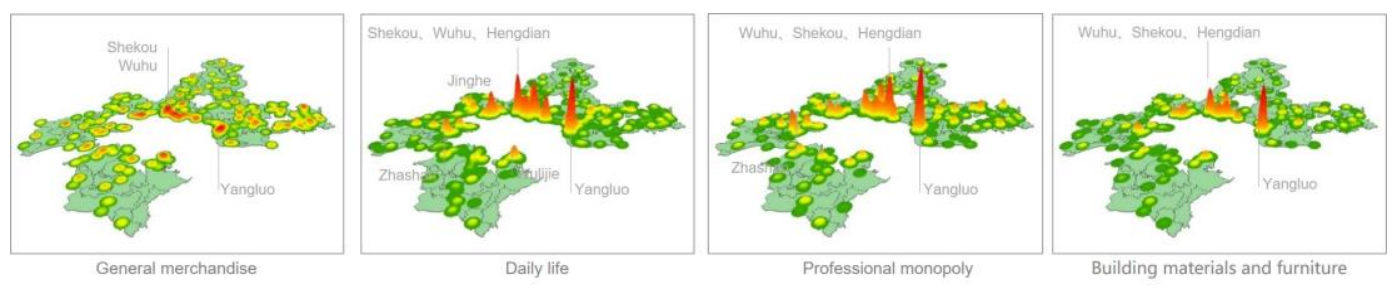

Figure 2 Spatial distribution pattern of entity retail business in small towns in Wuhan(2014) 


\subsection{Unbalanced Shrinkage of Small Towns}

The change of comprehensive development index is used to measure the growth and shrinkage of small towns. If the comprehensive development index declines, it can be defined as the shrinkage of small towns, and vice versa. This research measured the shrinkage degree of small towns in Wuhan in three periods: 2004-2009, 2009-2014 and 2004-2014. The results show that from 2004 to 2009, there was a large area of shrinkage of small towns in Wuhan (FIG.3). More than 50 small towns showed varying degrees of shrinkage, but most of them showed small extent of shrinkage. Only Yangluo, Tianhe, Dongshan, Zhengdian and other small towns, concentrated in the northern part of the main downtown, showed relatively high degree of shrinkage. From 2009 to 2014, small towns in Wuhan showed an overall growth trend. But there were still 17 small towns which were far away from the main downtown got a shrinkage, such as Changxuanling, Xinchong, Baiquan, Caijiacha, Yuxian, Xiaosi and other small towns, mainly concentrated in the northern Huangpi district and the western Caidian district. Small towns near the main downtown showed a significant growth pattern, especially small towns such as Yangluo, Wuhu, Jinkou and Zhashan, which showed an increase of more than 0.1. On the whole, during the period of 2004-2014, small towns in Wuhan have showed a pattern of "unbalanced shrinkage" which coexists with significant growth and shrinkage. The shrinking small towns were mainly concentrated in Huangpi district, Dongxihu district, the west of Caidian district and the middle of Xinzhou district. The growing small towns are concentrated in the first circle layer outside the main downtown and some small towns in the south of Jiangxia district and the east of Xinzhou district.

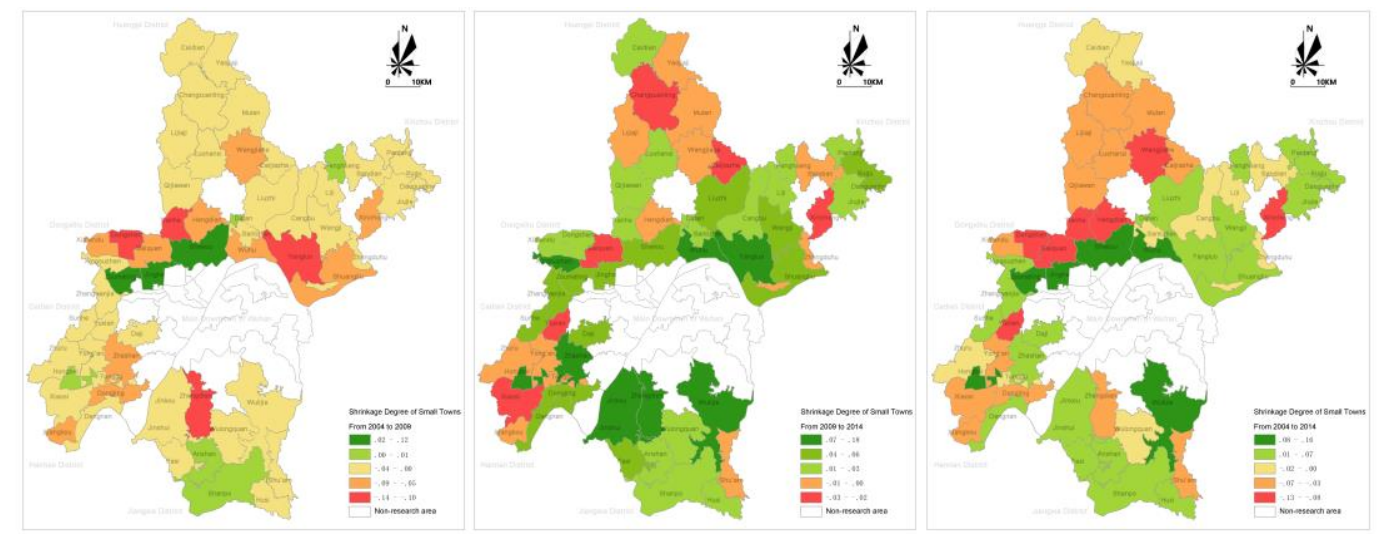

Figure 3 Shrinkage degree of small towns in Wuhan (2004-2009, 2009-2014, 2004-2014)

At the same time, the research measured the shrinkage degree of small towns from the single dimension of population (FIG.4). The results show that from 2004 to 2009, 45 small towns in Wuhan experienced population shrinkage, covering all six districts. The population shrinkage of Huangpi district is the most serious, especially the small towns like Shekou, Liuzhi, Qijiawan, Luohansi, Hengdian, Yaojiaji and Caidian, whose population fell by more than 7,000. From 2009 to 2014, only 10 small towns experienced population decline, which was quite different from the previous stage in terms of population evolution space. Based on a ten-year investigation from 2004 to 2014, it is found that the population of small towns in Wuhan has a development pattern of "shrinkage in the north, growth in the west, growth and shrinkage coexists in the south and east", and presents a circle structure of "shrinkage in the periphery towns and growth in the main downtown". Further analysis from the district level shows that the population of six remote districts in Wuhan are all decreased from 2004 
to 2014 (FIG.5), but the decrements are significantly different. Xinzhou district and huangpi district had the largest total population reduction, with 217,000 and 154,000 respectively. While in Caidian district, Dongxihu district and Hannan district, the population decline was no more than 30,000, among which Caidian district has the smallest decline, only 13,000 . In terms of the shrinkage degree of population, the most severe one is Dongxihu district, reaching 0.41 , followed by Xinzhou district $(0.35)$ and Jiangxia district $(0.37)$, and the least significant one is Caidian district (0.17).

By comparing the above two calculation results, it is found that there is a significant difference between the two methods of measuring the shrinkage degree of small towns. Although population is the most direct variable to measure the shrinkage of small towns, as a complex multi-dimensional feature, the "unbalanced shrinkage" of small towns cannot be measured independently by a single index, and a multi-dimensional evaluation system must be established to scientifically identify the growth and shrinkage of small towns.

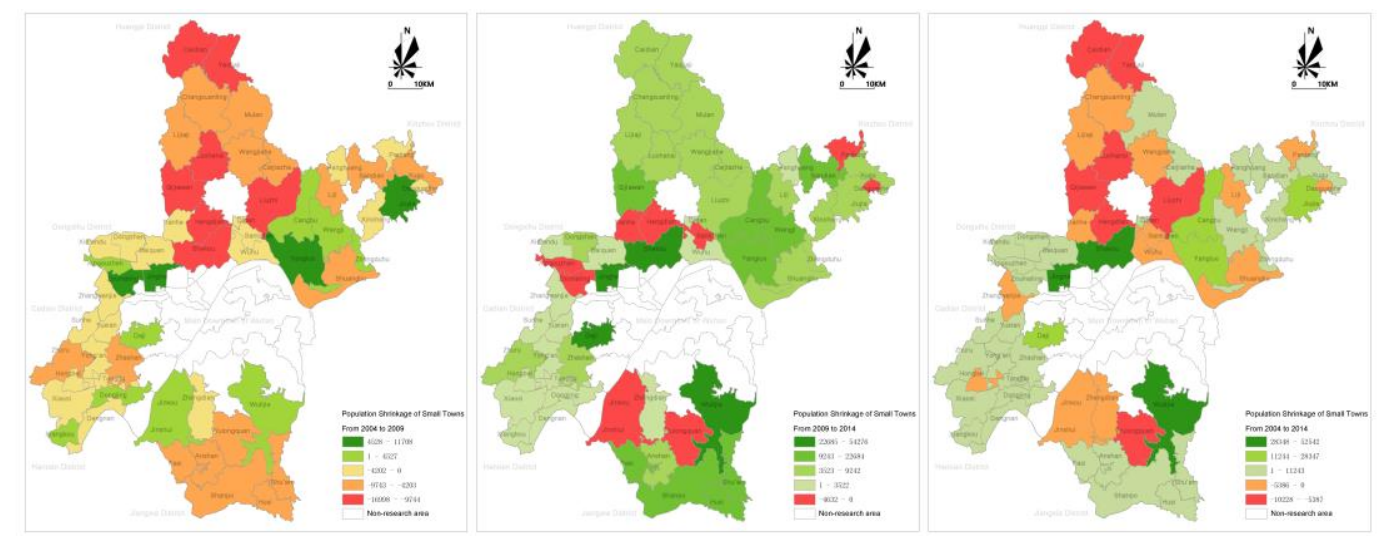

Figure 4 Population shrinkage of small towns in Wuhan (2004-2009, 2009-2014, 2004-2014)

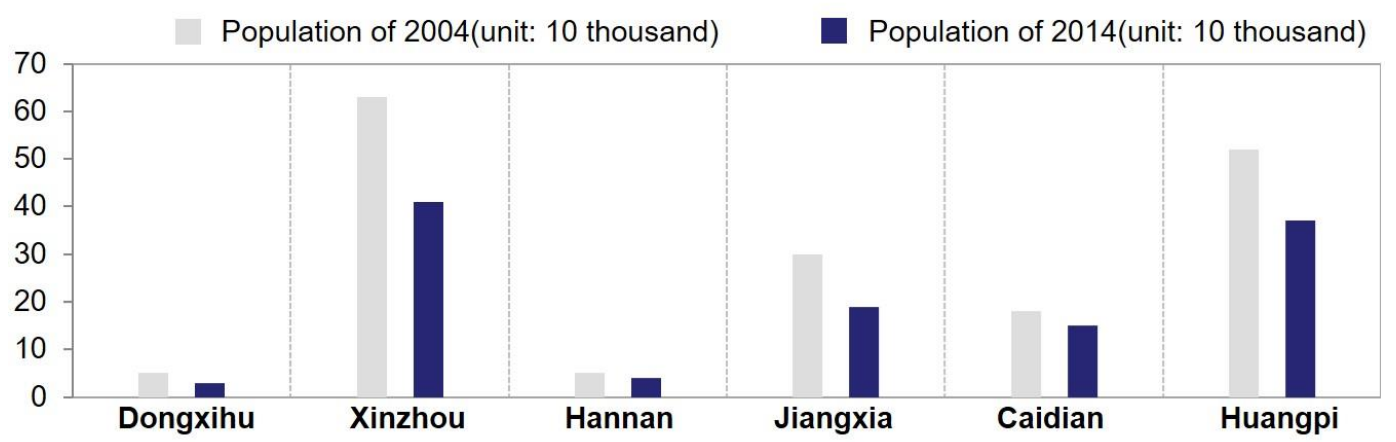

Figure 5 Population of six districts of Wuhan in the year of 2004 and 2014

\section{Discussion and Conclusion}

\subsection{Formation Mechanism of the "Unbalanced Shrinkage"}

The above results show that the small towns in Wuhan have shown a certain trend of unbalanced shrinkage, with a regional unbalanced spatial characteristic. A comprehensive interpretation of the internal characteristics of regional unbalanced shrinkage found that the formation of this shrinkage pattern lies in the unbalanced supply of city institutions, 
centripetal delivery of social capital and reconstruction of regional division of labour network.

\section{(1) Unbalanced supply of institutions}

The effective supply of upper institutions will significantly affect the social and economic development and space construction process of small towns. Since 2004, Wuhan has issued a series of policies to support the development of its peripheral small towns (Table 1). Due to the bias and preference of the government-led institutional supply, the small towns present regional unbalanced institutional environment. It has become the general trend of Wuhan's development to put public resources and social capital into orderly groups around key towns, central towns and new towns. Especially since 2010, according to the development strategy of "upgrading the main city and expanding the new city", Wuhan has further increased the investment and construction in the new city, formulated the regional employment and housing balance plan, and supported the gradient transfer and agglomeration distribution of urban population and industries. The new towns such as Zhashan, Shekou, Wuhu, Yangluo, with the aid of regional public service facilities, further enhance their industrial development and economic strength, leading to the further intensification of the polarization trend of regional development. On this basis, the regional growth poles have gradually formed, such as Yangluo, Zhashan, Wuhu, etc. For example, Wuhu, the new town in the north, is in a leading position in Huangpi district with the construction of transportation facilities such as new Huangwu Highway, Hankou north road, the fourth ring road and regional functional facilities such as Hankou north market group and Taichuang zone (FIG. 6).
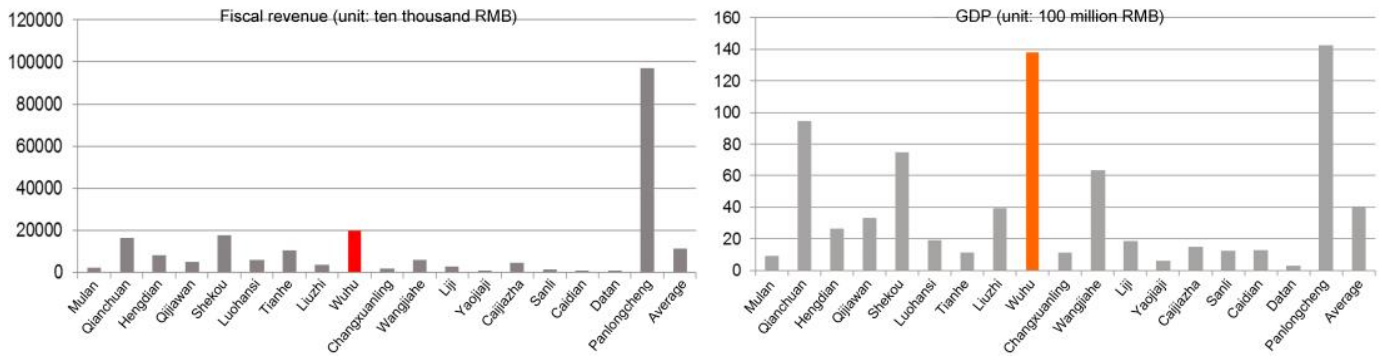

Figure 6 Comparison of fiscal revenue and GDP between Wuhu and other towns in Huangpi district in 2014

Table 1 Evolution of policy and institutional supply of small towns in Wuhan from 2004 to 2014

\begin{tabular}{|l|l|l|l|}
\hline Time & Policy/ institution & Content & Effect \\
\hline 2004 & $\begin{array}{l}\text { Opinions on } \\
\text { speeding up the } \\
\text { construction of } \\
\text { small towns }\end{array}$ & $\begin{array}{l}\text { Developing key towns, } \\
\text { accelerating investment in } \\
\text { infrastructure and public } \\
\text { service facilities and guiding } \\
\text { the injection of social capital }\end{array}$ & $\begin{array}{l}\text { Effectively promoting } \\
\text { construction and development of } \\
\text { Yangluo, Wuhu, Zoumaling, } \\
\text { Xingou, Xiangkou, Zuoling, Shekou } \\
\text { and other key towns }\end{array}$ \\
\hline $\begin{array}{l}\text { Urban agriculture } \\
\text { development of } \\
\text { Wuhning }\end{array}$ & $\begin{array}{l}\text { Promoting the construction } \\
\text { of urban agricultural } \\
\text { industrial zones }\end{array}$ & $\begin{array}{l}\text { Six industrial parks have been } \\
\text { formed, including Wuhu to } \\
\text { Shuangliu, Dongxihu, Caidian to } \\
\text { Hannan, Huangpi to Xinzhou and } \\
\text { Jiangxia }\end{array}$ \\
\hline
\end{tabular}




\begin{tabular}{|c|c|c|c|}
\hline 2008 & $\begin{array}{l}\text { 11th five-year plan } \\
\text { of city spatial } \\
\text { layout in Wuhan }\end{array}$ & $\begin{array}{l}\text { Delimiting six new town } \\
\text { clusters and six ecological } \\
\text { green wedges }\end{array}$ & $\begin{array}{l}\text { Promoting the rapid growth of } \\
\text { towns within the new town cluster } \\
\text { and limiting the development of } \\
\text { towns within the ecological green } \\
\text { wedge; }\end{array}$ \\
\hline 2010 & $\begin{array}{l}\text { Master plan of } \\
\text { Wuhan }\end{array}$ & $\begin{array}{l}\text { Determine the four-level } \\
\text { town system of "main city - } \\
\text { new town - central town - } \\
\text { general town" }\end{array}$ & $\begin{array}{l}\text { Strengthening the supporting } \\
\text { facilities of the new town and the } \\
\text { central town and improve the } \\
\text { construction scale of the central } \\
\text { town }\end{array}$ \\
\hline 2011 & $\begin{array}{l}\text { Opinions on } \\
\text { accelerating the } \\
\text { implementation of } \\
\text { new urbanization }\end{array}$ & $\begin{array}{l}\text { Cultivating the development } \\
\text { of central town, } \\
\text { characteristic town as a } \\
\text { strategy to promote new } \\
\text { urbanization }\end{array}$ & $\begin{array}{l}\text { Further strengthening the } \\
\text { development level of the central } \\
\text { town. And show policy preference } \\
\text { on land indicators, financial supply, } \\
\text { and public facilities construction }\end{array}$ \\
\hline 2012 & $\begin{array}{l}\text { Notice on the pilot } \\
\text { reform of the } \\
\text { administrative } \\
\text { system of } \\
\text { economically } \\
\text { developed towns }\end{array}$ & $\begin{array}{l}\text { Carrying out a reform of } \\
\text { strengthening } \\
\text { administrative system of } \\
\text { expanding the power of } \\
\text { economically developed } \\
\text { towns }\end{array}$ & $\begin{array}{l}\text { Three regional growth cores have } \\
\text { been formed, including Zhashan } \\
\text { and Wuhu }\end{array}$ \\
\hline
\end{tabular}

\section{(2) Centripetal delivery of social capital}

The Neo-Marxist theory holds that the spatial production of urban construction environment is the result of social capital control and action (ZHANG and CAI 2006). The effective allocation of government and social capital has become the main driving force for the social and economic development of small towns. Before 2004, with a small agglomeration effect of the central downtown of Wuhan, the capital investment in small towns remained relatively stable, which effectively promoted the construction of facilities in small towns. But with the rapid development of the central downtown of Wuhan since 2005, the capital appreciation effect and effective recovery rate of the central downtown are much higher than the peripheral small towns, causing the government finance and social capital of the traditional small towns to turn to the central supply. Especially the industrial capital, mainly concentrated in the industrial parks in urban development areas, which leads to the general lack of industrial support and vitality in peripheral small towns. At the end of 2010, the "Industrial doubling plan" of Wuhan has put forward that the layout of industrial project and allocation of development factors would mainly located in nine key blocks, which only covers three small towns, which are Yangluo, Shekou and Zhashan. In 2014, the comprehensive planning of the four major blocks of Wuhan proposed that industrial enterprises should be centrally distributed, new town centres should be centrally built, supporting infrastructure should be centrally built, and "industrial agglomeration, spatial concentration and land use intensification" should be strengthened. At the same time, the establishment of industrial parks in peripheral small towns is prohibited, especially those located in efficient and characteristic agricultural circles. These requirements directly make it difficult for the peripheral street towns with a certain development foundation to play their important carrier role in the urbanization process due to a lack of proper support, and the local 
industrial development of the towns and villages is limited, and the towns and villages all show the trend of decline. Statistics show that during 2004-2014, the new construction lands of the small towns, with an area of 175.1 square kilometres, are mainly located in the first circle around the main city, such as Yangluo, Shekou, Tianhe, Wuhu, Zhashan, Jinkou and other towns (Fig.7). While the area of construction lands for small towns outside the first circle has only increased by square kilometres. Due to a lack of injection of social capital, the peripheral small towns generally face the dilemma of slow space growth and sluggish development.
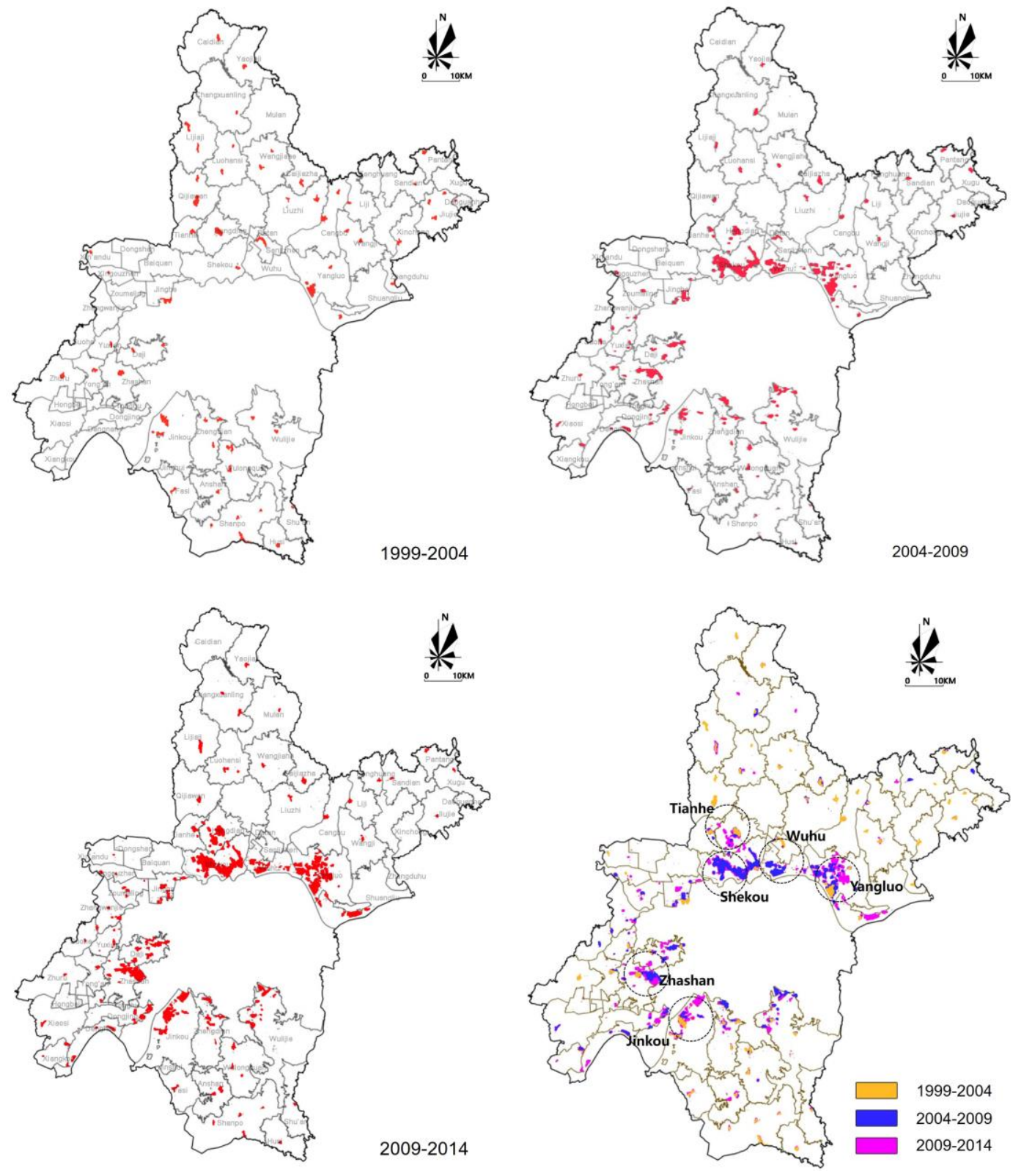

Figure 7 Distribution of new construction land in small towns from 1999 to 2014

\section{(3) Reconstruction of regional division of labour network}

According to social network theory, urban and rural social and economic development is attributed to the spatial flow effect of material resources, in which material resources are 
mobile elements and social and economic network is the connection bridge of element circulation. Since 1978, Wuhan has long valued urban areas over rural areas, leading to the solidification of the urban-rural dual structure. Small towns become the connection bridge and transfer station connecting the circulation of material resources between "urban area" and "rural area", thus gradually forming a stable "city-town-village" three-level division of labour network within the scope of the city. However, with the introduction of policies in China such as the new socialist countryside in 2005, the beautiful countryside in 2009 and the rural revitalization in 2017, Wuhan has made great efforts to improve rural construction and promote the overall planning and integrated development of urban and rural areas. After more than ten years of rural construction, Wuhan has basically achieved the integration of urban and rural facilities, which has weakened the public service function of small towns to the countryside. At the same time, the industrial capacity of small towns declines, and the functions of small towns fade as a result of transmission. There is a phenomenon of "city-village" cross-level factor flow between urban and rural areas in Wuhan city, and the service shrinkage of function decline generally occurs in small towns.

In addition, Wuhan has focused on the development of rural tourism industry since 2010, and formed a number of unique tourist towns relying on their own landscape resources and tourist attractions, such as Caidian, Yaoji, Changxuanling, Mulan, Liji, Wangjiahe, Daoguanhe, Suohe, Yong'an, Fasi and other towns. In accordance with the idea of key transformation and upgrading, 74 beautiful villages and 15 central villages (communities) have been built successively by adopting four models, including the mode of combining agriculture with tourism, the mode of combining poverty alleviation with development, the mode of building new countryside and the mode of developing characteristic agricultural products. The villages gradually get rid of the dependence on towns, which leads to the significant weakening of township functions.

\subsection{Response Path Adapted to the "Unbalanced Shrinkage"}

As mentioned above, under the influence of institution, capital and network, the development of small towns in Wuhan city shows a significant feature of "unbalanced shrinkage". In spite of the regional integration development, the shrinkage of small towns has its inevitability and rationality. However, this kind of shrinkage also adversely affects the healthy development of social economy in small towns. Therefore, it is necessary to adjust the development mode of small towns, explore the development path of small towns adapted to the unbalanced shrinkage, so as to promote the healthy development of small towns and urban division of labour network.

(1) Integrating into the regional differential development pattern and striving for the institutional dividend

To cope with the influence of regionalization, the self-cognition initiative of small towns should be exerted firstly. On the one hand, small towns need to seek differentiated and characteristic development in regional competition, give full play to their advantages in region, culture, resources and location, and seek a breakthrough in development based on characteristics and advantages, so as to eliminate the adverse impact of contractive elements. On the other hand, small towns should extend the industrial chain and form linkage development with surrounding industries to integrate into regional development pattern and improve regional competitiveness based on their own characteristics, development capabilities and regional development requirements. 
On this basis, small towns should actively strive for institutional dividends. In the process of institutional supply, the government always gives priority to the overall development efficiency of the city, while lacks independent thinking of individual small towns. Therefore, small towns must actively acquire the preference of urban institution to better support their own development. To be specific, on the one hand, during the process of regionalization development, small towns should face up to the reasonable shrinkage under the influence of regional environment, and effectively adjust, restructure or streamline the regional and internal functions of small towns according to the changes of regional environment. And then they should pay attention to the reallocation and selection of resources after shrinkage and expansion, so as to meet the needs of regional development. On the other hand, small towns should change the development mode from the self-centred mode to the regional cooperation and become the important node of the network town cluster with multi-centre connection. In the meantime, the city government need to targeted put forward the strategies adapted to the "shrinkage" for the small towns in the overall urban planning, including regional economic collaboration, urban and rural public service facilities sharing, town and country information interaction between urban and rural areas, ecological network and other dimensions, with a view to improve the precision of unbalanced resource allocation and delivery, scientific nature and rationality.

\section{(2) Promoting an industrial transformation and attracting the market release of social capital}

The low level industrial structure and low efficiency industrial type are the important factors that cause the sluggish industrial development and economic shrinkage of small towns. For small towns in Wuhan, due to the spatial attenuation and selective orientation of radiation from the main downtown, most of them still mainly rely on agriculture and traditional industry, while the tertiary industry is weak. However, the production benefits of agricultural products gradually tend to be saturated, and the development of traditional industries is mostly in a state of small scale, low level, poor benefits and short industrial chain. It is not only unable to support local residents' jobs, but also difficult to effectively realize industrial agglomeration and driving effect. These small towns supported by traditional industries are prone to economic shrinkage due to their difficulty in adapting to the requirements of economic development in the post-industrial era in regional competition.

Therefore, small towns must adjust the industrial structure, reorganize and make full use of internal factor resources, strengthen and expand the industrial chain, and improve the industrial system to form an industrial development model of agglomeration and linkage. At the same time, we should abandon the unsustainable resource-consuming industries in the adjustment of industrial structure, and realize the intensive transformation, so as to lay a good foundation for the healthy and sustainable development of small towns. In addition, the injection of social capital also provides a new opportunity for the renewal of urban built environment and space reproduction. According to David Harvey's secondary circuit theory, the effective delivery of capital plays a significant role in stimulating the social and economic development of cities and towns. Therefore, in the shrinking small towns, we should return to the capital market, use urban industrial transformation to attract capital backflow and stimulate urban space reproduction.

(3) Improving the living environment and promoting intensive use of land 
In 2019, China's urban and rural planning has officially entered the era of spatial planning. Land improvement oriented by intensive utilization of land resources has become an important part of space governance. However, the construction of small towns is blindly expanded with a widespread use and waste of land for a long time under the stimulation of land finance. Although the Wuhan government has restricted the construction scale of small towns in terms of land transfer index, the lack of forward-looking spatial planning has led to the lack of orderly guidance for the construction of small towns, and the phenomena of land waste, environmental pollution and farmland occupation still exist. Along with the phenomenon of population outflow and economic deactivation, the living space, commercial space, public space and industrial space in small towns are all in the state of vacant and decaying to varying degrees, which further worsens the dirty and poor urban environment in small towns. Therefore, it is particularly important to promote the intensive use of land and improve the living environment of small towns.

For shrinking small towns, the increment of urban land should be reduced, the existing land stock should be used for follow-up land development as much as possible, and the idle urban construction land caused by the sluggish economy should be revitalized. And the government should weaken the concept of land finance, strengthen the improvement of urban living environment, supply urban environmental sanitation facilities, and strengthen the supervision of urban land development, utilization and construction with the goal of creating a good urban living environment.

For small towns that have not shrunk, we must adhere to the development principle of intensive use of land and efficient use of space in small towns, and carry out appropriate incremental development on the basis of not reducing the development efficiency of urban stock land, so as to avoid the decline of energy efficiency of urban land and enter the shrinkage trap of "land overdraft". At the same time, urban living environment should also be improved, and the supervision mechanism of urban living space protection should be done well, to avoid population loss and urban deactivation caused by uninhabitable urban.

\section{(4) Building a stable regional division of labour network}

While facing up to the shrinkage of small towns, China's unique "semi-urbanization" phenomenon cannot be ignored. The basic social security function of small towns is still an important link in the relationship between towns and villages. Especially for the small towns in the outer suburbs of Wuhan, most of them are not highly urbanized, and also not completely divorced from the leading mode of agricultural production. Those small towns still have the structural function of linking urban and rural relations, promoting the flow of factors and serving rural revitalization. A healthy relationship among city, towns and villages is still an important problem in the process of urbanization. Therefore, small towns should not only optimize their service functions, social functions and ecological and cultural functions, but also further strengthen the linkage development relationship in the "city, town and village", "town and town" and "village and village", so as to build a network citytown-village hierarchical model. Small towns also need to integrate scattered elements of regions and grass-roots units, form a network of industrial interaction, service sharing and transportation interconnection supporting system, and build a networked and flat multidimensional city-town-village space system, in order to realize the interconnection of elements and resource sharing in the overall shrinkage process. In this way, the service efficiency of grassroots public service facilities can be strengthened, and the relationship 
between towns and villages can be reshaped to prevent the rupture of the single linear hierarchy relationship formed by shrinkage and to resolve the inertia of dependence on the original linear hierarchy system and its negative impact.

\section{Acknowledgments}

This research was supported by the National Science Foundation of China (51878306).

\section{References}

Oswalt P (2006) Shrinking cities, Ostfildern, Germany: Hatje Cantz Verlag.

Glock B, Häussermann H. (2004) "New trends in urban development and public policy in eastern Germany: dealing with the vacant housing problem at the local level", International Journal of Urban and Regional Research, Vol. 28 No. 4 (April).

Johnson, K., \& Johnson, K. (2006) "Demographic trends in rural and small town America", Demographic Trends in Rural \& Small Town America, Vol. 44 No. 1 (January).

Bontje M, Musterd S. (2012) “Understanding Shrinkage in European Regions", Built Environment, Vol. 38 No. 2 (February).

Downs A. (1997) “The challenge of our declining big cities", Housing Policy Debate, Vol. 8 No. 2.

Saori K, Polivka J. (2008) "Shrinking of Japanese middle sized cities", Shrinking Cities Complete Works, Vol. 19 No. 3 (March).

ORTIZ-MOYA F.(2015) "Coping with shrinkage: rebranding post-industrial Manchester", Sustainable Cities \&Society, Vol. 22 No. 7 (July).

Martinez Fernandze C, Audirac I, Fol S, et al. (2012) "Shrinking cities: Urban challenges of

Globalization", International Journal of Urban and Regional Research, Vol. 36 No. 2 (February).

CHEN Yulu, LI Jingsheng, YANG Chen, QIN Mengdi (2018) "Research on the Shrinking of Small Cities in Germany: A Case Study on Sachsen", Development of Small Cities \& Towns, Vol. 36 No. 11 (November).

DU Zhiwei, II Xun (2018) "Characteristic and Mechanism of Urban Growth and Shrinkage from Demographic Change Perspective: A Case Study of Dongguan", Scientia Geographica Sinica, Vol. 38 No. 11 (November).

DU Zhiwei, II Xun (2017) “Growth or shrinkage: New phenomena of regional development in the rapidly-urbanising Pearl River Delta", Acta Geographica Sinica, Vol. 72 No. 10 (October).

LIU Chunyang, YANG Peifeng (2017) “A Comparative Study on the Motivation Mechanism and Performance Characteristics of Chinese and Foreign Shrinking Cities", Modern Urban Research, No. 3 (March). 
LI Yanqun, GENG Hong, GAO Peng (2018) “A Discussion into the New Development Pattern of Town and Village under the Guidance of Smart Decline", Development of Small Cities \& Towns, Vol. 29 No. 4 (April).

GAO Zhe, YIN Ningwei, TONG Xinyi, LI Dongxin, GU Jiang (2019) "Shrinkage under Urban Growth: A Case Study of Wuhan City", Tropical Geography, Vol. 39 No. 1 (January).

LI Xun, LI Xianfeng, DENG Jiayi (2019) “The Growth and Shrinkage of China's Rapidly Urbanizing Areas from the Perspective of Property Rights: A Case Study of Dongguan", Tropical Geography, Vol. 39 No. 1 (January).

ZHANG Yingxiang, CAI He (2006) "Capitalist and urban social change-perspective of NeoMarxist urban theory". Urban Studies, Vol. 13 No. 1 (January)

Wang Mingtao (1999) "Deviation and mean square deviation decision method for weight determination in evaluation index", China Soft Science, Vol. 26 No. 8 (August) 